\title{
Effects of temperature on uranium(VI) solution speciation
}

\author{
BEN URICK ${ }^{1}$, CHRISTOPHE TOURNASSAT ${ }^{2,3}$ AND RUTH \\ TINNACHER $^{1}$ \\ ${ }^{1}$ California State University East Bay \\ ${ }^{2}$ Lawrence Berkeley National Laboratory \\ ${ }^{3}$ University of Orléans \\ Presenting Author: burick@horizon.csueastbay.edu
}

At future nuclear waste repositories, elevated temperatures have to be expected due to the initial thermal loading of waste packages and the continued release of decay heat over time. As a result, contaminant transport models for early-release scenarios will have to consider potential effects of temperature on contaminant mobility, such as mineral transformations and subsequent changes in mineral surface characteristics, and the temperature dependence of radionuclide diffusion and adsorption coefficients. Furthermore, the predictions of any temperaturedependent radionuclide surface complexation or diffusion model will largely depend on an accurate representation of radionuclide solution speciation at elevated temperatures. Hence, the goal of this study is to gain a better understanding of potential changes in radionuclide solution speciation as a function of temperature, using uranium(VI). In particular, we aim to elucidate the underlying parameters and processes that contribute to the apparent changes in U(VI) solution speciation, and to systematically decouple them in order to evaluate their relative contributions to temperature-induced shifts in dominant U(VI) solution species. For this purpose, we simulated U(VI) solution speciation as a function of $\mathrm{pH}$, partial pressures of $\mathrm{CO}_{2}$ and temperature $\left(25-80{ }^{\circ} \mathrm{C}\right)$, using PHREEQC with the ThermoChimie $9 \mathrm{~b} 0$ database. Based on a review of the ThermoChimie and NEA databases and other literature, we also assessed the lack of thermodynamic data for the formation of some U(VI) solution complexes.

For atmospheric $\mathrm{CO}_{2}$ conditions, we observed that the dominance of the uranyl ion $\left(\mathrm{UO}_{2}{ }^{2+}\right)$ shifts to lower $\mathrm{pH}$ values, while the dominance of $\mathrm{U}(\mathrm{VI})$-carbonato solution complexes shifts to higher $\mathrm{pH}$ with increasing temperatures. As a result, $\mathrm{U}(\mathrm{VI})$-hydroxide complexes become dominant over a broader $\mathrm{pH}$ range at elevated temperatures. At this point, we have identified three main factors contributing to these trends: (1) the shift of $\mathrm{pH}$ neutrality to lower $\mathrm{pH}$ values due to the endothermic nature of the water dissociation reaction; (2) the lower dissolution of $\mathrm{CO}_{2}(g)$ in solution with higher temperatures, and (3) the temperature-dependence of $\mathrm{U}(\mathrm{VI})$ solution complexation constants. All of these factors will be discussed in further detail in our presentation.

This research is funded through DOE's Nuclear Engineering University Program (DE-NE0008683 and DE-NE0008938). 